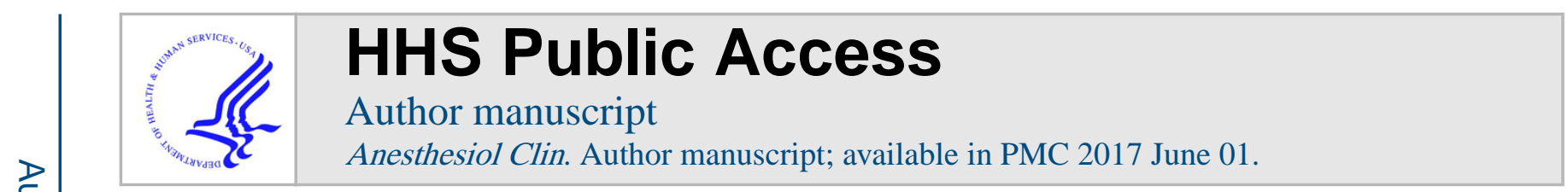

Published in final edited form as:

Anesthesiol Clin. 2016 June ; 34(2): 255-269. doi:10.1016/j.anclin.2016.01.001.

\title{
Imaging Pain
}

\section{Katherine T. Martucci, PhD and Sean C. Mackey, MD, PhD*}

\section{Keywords}

Chronic pain; Neuroimaging; MRI; Resting-state networks; MVPA; Brain-based therapies

\section{INTRODUCTION}

Chronic pain affects more than 100 million adults and accounts for approximately $\$ 600$ billion annually in medical costs and lost productivity. ${ }^{1}$

The complex neural mechanisms that occur to amplify and maintain chronic pain are poorly understood. Neuroimaging pain research holds great promise for the development of new and effective treatments through advancing our understanding of these complex mechanisms.

Neuroimaging research findings show that chronic pain is different from acute pain. Chronic pain can become a disease in its own right that occurs following initial injury, which then progresses to a chronic state within the central nervous system (CNS). Although other body systems are also involved in the initiation and maintenance of chronic pain, ${ }^{2}$ neuroimaging has allowed for increased understanding of how the CNS is involved in chronic pain.

Types of neuroimaging used to study chronic pain

- $\quad$ PET

- $\quad$ Electroencephalography (EEG)

- $\quad$ Magnetoencephalography (MEG)

- $\quad$ Single-photon emission computed tomography (SPECT/CT)

- $\quad$ MRI

Examples of chronic pain conditions studied using neuroimaging

- $\quad$ Chronic low back pain (cLBP) ${ }^{3}$

- $\quad$ Fibromyalgia $(\mathrm{FM})^{4}$

- $\quad$ Osteoarthritis $(\mathrm{OA})^{5}$

- $\quad$ Complex regional pain syndrome (CRPS) ${ }^{6}$

*Corresponding author: Department of Anesthesiology, Perioperative, and Pain Medicine, Division of Pain Medicine, 1070 Arastradero Road, Suite 200, MC 5596, Palo Alto, CA 94304-1345. smackey@stanford.edu.

Conflict of Interest Statement: Authors have no conflicts of interest to declare. 
- $\quad$ Phantom limb pain, chronic migraine ${ }^{7}$

- $\quad$ Chronic pelvic pain $(\mathrm{CPP})^{8,9}$

- $\quad$ Peripheral neuropathy $(\mathrm{PN})^{10}$

In addition to advancing the study of chronic pain, the evolution of neuroimaging technology has opened a window to the brain that allows us a more complete understanding of the basic physiologic and pathophysiologic mechanisms of pain signal processing and the related subjective experience of pain itself.

Examples of neuroimaging research of pain processing

- $\quad$ Acute pain in healthy volunteers ${ }^{11}$

- $\quad$ Acute pain in animals ${ }^{12}$

- $\quad$ Animal models of chronic pain ${ }^{13}$

Several experiential factors influence the experience of pain. Neuroimaging has allowed for the study of how these factors interact with and impact pain perception by studying related changes in brain activity.

Examples of pain modulatory factors studied using neuroimaging

- $\quad$ Attention $^{14}$

- Anticipation $^{15}$

- $\quad$ Empathy 16

- $\quad$ Placebo $^{17}$

- $\quad$ Effects of meditation ${ }^{18}$

- $\quad$ Fear/anxiety 19

- $\quad$ Reward $^{20}$

The present review focuses specifically on the use of neuroimaging, specifically the most widely used neuroimaging technology of MRI, and observed CNS changes in various chronic pain conditions (Box 1) As used here in this review, we refer to "neuroimaging" as meaning imaging of the spinal cord, brainstem, and brain. Neuroimaging of peripheral nerves is beyond the scope of this review.

\section{Box 1}

\section{MRI protocols}

MRI is a widely used neuroimaging tool for the study of chronic pain. It combines a strong magnetic field with radiofrequency pulses to display high spatial-resolution structural images. Multiple imaging protocols using MRI have been developed and allow for measurement of changes in brain structure and activity.

Voxel-based morphometry, cortical thickness analysis: measures the density and distribution of gray matter. 
Diffusion tensor imaging, functional anisotropy: measures the density and distribution of white matter.

Functional MRI (fMRI): indirect measure of brain activity based on changes in blood oxygenation level (referred to as the BOLD signal) ${ }^{21}$

Magnetic resonance spectroscopy: measures relative concentrations of metabolites ${ }^{22}$

Arterial spin labeling fMRI: measures changes in global and regional blood flow by using magnetically labeled protons in the blood as an endogenous $\operatorname{tracer}^{23}$

Neuroimaging protocols can collect data from patients with chronic pain when they are at rest, performing various tasks, or undergoing interventions and procedures.

\section{Examples of Neuroimaging Nonrest Conditions}

- $\quad$ Application of physical stimuli

- $\quad$ Heat pain

- Pressure

- $\quad$ Movement of the body (eg, limb) to evoke pain

- $\quad$ Tasks

- $\quad$ Showing emotion-evoking images

- Working memory tasks

- Decision-making tasks

Data from Refs. ${ }^{21-23}$

\section{ANATOMIC AND FUNCTIONAL SUBSTRATES}

\section{Basic Sequence of Mechanisms and Structures Involved in Pain Processing}

1. Noxious stimuli trigger signals in the peripheral nerves. Peripheral nerves that relay nociceptive information include the following:

- A-delta nerve fibers: These fibers transmit "first-pain" signals, the pricking, sharp sensations felt immediately after a stimulus.

- C fibers: These fibers transmit "second-pain" signals, the dull, aching, throbbing pain felt 1 to 2 seconds after a stimulus. ${ }^{24}$

2. The peripheral nerve fibers synapse in the dorsal horn of the spinal cord.

3. Interneurons are responsible for inhibitory/excitatory modulation at the level of the spinal cord.

4. Secondary spinal projection neurons transmit nociceptive information to the brainstem regions, including the rostral ventral medulla and periaqueductal gray (PAG). 
5. Nociceptive information is further modulated in the brainstem and then relayed to the thalamus.

6. The nociceptive signals are transmitted from the thalamus to the cortex where they are interpreted as pain.

7. Several cortical regions are involved in pain processing, including the primary somatosensory cortex, secondary somatosensory cortex, insular cortex, prefrontal cortex, and motor cortex (for review, see Ref. ${ }^{25}$ ).

In chronic pain, these systems are thought to be upregulated, causing a state of "central sensitization." ${ }^{26}$ Central sensitization is the result of the following:

- Inflammation and sensitized receptors in the skin causing abnormal or increased nociceptive signals from peripheral nerves

- Lack of inhibition and/or increased excitation within the spinal cord, brainstem, and/or cortex

Neuroimaging allows for noninvasive measurement of altered activity in the spinal cord, brainstem, and brain, where pain modulation and central sensitization occur and contribute to chronic pain. ${ }^{27}$ Historically, neuroimaging researchers have focused their efforts on finding key brain regions that have altered structure and activity in individuals with chronic pain. The identification of specific brain regions implicated in mechanisms that support ongoing chronic pain may allow future targets for therapy.

Several key brain regions are known to play major roles in chronic pain. These regions most commonly function as regions of sensory and motor processing, affective and emotional aspects of pain, and high-order cortical processing and integration.

\section{IMAGING FINDINGS}

\section{Regional Changes in Brain Structure}

Numerous research studies have investigated brain structure in individuals with chronic pain typically using methods of voxel-based morphology (VBM) ${ }^{28}$ and cortical thickness analysis. ${ }^{29}$ Increased and decreased cortical thickness and gray matter density occur among several chronic pain conditions, including cLBP, ${ }^{3,30}$ fibromyalgia, ${ }^{31}$ temporomandibular disorders (TMD),${ }^{20}$ CRPS,${ }^{6}$ migraine, ${ }^{32}$ and in chronic visceral pain, such as irritable bowel syndrome (IBS). ${ }^{33}$ Newer research studies have investigated changes in gray matter among multiple types of chronic pain, such as CRPS, knee OA, and cLBP. ${ }^{34}$ Together, these studies show that key areas of gray matter differences are most often within the following:

- $\quad$ Somatosensory and motor cortex

- Insular cortex

- Subcortical regions including the thalamus and basal ganglia

- $\quad$ Parietal cortex

- $\quad$ Prefrontal cortex 
- Amygdala and hippocampus

Changes in gray matter are most commonly observed as decreases in regional gray matter density. These decreases in gray matter density may be associated with increased age-related gray matter atrophy. ${ }^{35}$ However, several studies show both regional increases and decreases in gray matter density. ${ }^{20}$ Thus, the primary cause of these changes is unclear. It is also unknown whether these observations represent preexisting differences in brain structure; in other words, that may predispose persons to chronic pain. Alternatively, the changes in gray matter density may result from the presence of chronic pain, for example, due to ongoing stress of the pain experience.

It is also unclear whether these changes may be functionally linked to the maintenance of chronic pain. Further, differences in gray matter structure may be specifically due to chronic pain, or may result from the many comorbid conditions or other factors often observed in conjunction with chronic pain, such as depression, sleep disturbance, or medication use. As an example of this, in a meta-analysis of structural brain changes in patients with FM, depression scores accounted for most of the changes in gray matter structure. ${ }^{36}$ Nonetheless, gray matter changes are likely not only due to depression, because these changes also have been observed in patients with cLBP experiencing very minimal levels of comorbid depression. ${ }^{3}$

Changes in white matter structure are also commonly observed in neuroimaging research studies of chronic pain. These changes represent the structural integrity of connections between brain regions. Diffusion tensor imaging (DTI) and fractional anisotropy are the primary technologies used to measure white matter structure within the brain. Differences in white matter structure have been observed among several chronic pain states, including TMD,${ }^{37}$ IBS,${ }^{38}$ and CPP. ${ }^{39}$

Newer research has measured changes in gray matter and white matter simultaneously. These studies have been conducted in patients with CRPS ${ }^{40}$ and $\mathrm{FM}^{41,42}$ and allow for increased understanding of the relationships between gray and white matter structural changes in chronic pain.

\section{Regional Changes in Brain Function}

Altered brain activity has been detected across multiple chronic pain syndromes. Most of the brain regions that demonstrate functional changes overlap with regions of observed structural change. ${ }^{43}$ Neuroimaging research studies often measure brain activity in individuals with chronic pain in response to painful stimulation, ${ }^{44}$ during emotional or cognitive tasks, ${ }^{45}$ in response to stress, ${ }^{46}$ or while patients continuously rate their ongoing pain. ${ }^{47}$

Similar to acute pain processing, multiple brain regions appear to play a functional role in chronic pain. ${ }^{48}$ Several key regions in the CNS consistently demonstrate altered function in chronic pain across numerous neuroimaging research studies, described as follows.

Primary somatosensory cortex and posterior insular cortex: 
- $\quad$ Regions typically associated with intensity coding of pain

- $\quad$ Altered activity (typically increased) in response to noxious stimulation

- $\quad$ Observed in cLBP, FM, CPP, and CRPS ${ }^{49}$

- $\quad$ Suggest altered intensity processing of pain in chronic pain

Secondary somatosensory cortex (SII):

- Region of higher-order sensory processing and integration

- Structural and functional alterations observed in this region ${ }^{50}$

Primary motor cortex, premotor cortex, and supplementary motor areas:

- Regions of motor processing and preparation of movement

- Structural and functional alterations have been observed in in $\mathrm{CPP}^{9,51}$

- Implicated in chronic pain due to close overlap of brain sensory and motor processes

Cerebellum:

- Functional changes often reported yet minimally discussed in the literature

- May be related to altered sensory-motor and emotional processing in the presence of chronic pain ${ }^{52}$

Prefrontal cortex (PFC):

- Includes the ventromedial PFC, dorsolateral PFC, and orbitofrontal $\mathrm{PFC}^{53}$

- Higher-order regions of cognitive processing and cognitive inhibition of pain

- $\quad$ Regions mediate the relationship between cognitive processes and chronic pain (for example see Ref. ${ }^{54}$ )

Parietal cortex:

- Includes the temporo-parietal junction, precuneus, and posterior cingulate cortex

- $\quad$ Regions are involved in introspection, mind wandering, and self-referential thought processes ${ }^{55}$

- Functional changes in chronic pain may reflect increased integration of thought processes with pain experience

Anterior insular cortex ${ }^{56}$ and anterior cingulate cortex ${ }^{57}$ :

- Regions related to the affective aspects of pain processing (such as the level of unpleasantness, negative context)

- $\quad$ Altered function in chronic pain ${ }^{58}$

Amygdala ${ }^{59}$ and hippocampus ${ }^{60}$ :

- $\quad$ Regions involved in emotion, fear, and memory processes 
- Functional alterations related to psychological aspects of chronic pain, including altered fear and emotional processing

- $\quad$ Scale-based correlations of altered emotion processing with altered brain structure and function

- $\quad$ Alterations due to general changes in limbic and memory networks because fear avoidance (of movement) is not responsible for these changes ${ }^{61}$

Subcortical, midbrain, and brainstem regions:

- Functional alterations suggest altered brain circuits and modulation of nociceptive information

- Thalamic lesions implicated in central pain ${ }^{62}$ and altered thalamic activity in other chronic pain states as well

- $\quad$ Basal ganglia ${ }^{63}$

- Midbrain regions, including the ventral tegmental area, ${ }^{64,65}$ altered mechanisms of reward, punishment, and dopamine function

Brainstem regions:

- $\quad \mathrm{PAG}^{66}$ may signify disrupted regulatory control of pain ${ }^{67}$

- $\quad$ Because of its small size, highly complex structure, and the multifunctional heterogeneity of the brainstem, thus far there is limited study within this region

Spinal cord:

- $\quad$ Altered activity observed using electrophysiology, typically in animal models of chronic pain

- $\quad$ MRI of the cervical spinal cord in healthy individuals ${ }^{68,69}$

- Technology is evolving, and in the future may be useful for the study of chronic pain $^{70}$

\section{Network-Based Changes in Brain Function}

Resting-state functional MRI (fMRI) focuses on relationships of activity across multiple brain regions, or "networks." Correlated activity between regions within a network indicates that regions are functionally connected. ${ }^{71}$ Resting-state fMRI is used to collect information about the natural state of brain activity because the data are collected while participants are at rest. It is therefore ideal for patients with chronic pain because no additional sensory or cognitive stimulation is necessary. Functional connectivity is measured as the correlation of low-frequency oscillations in neural activity among brain regions. Differences in functional connectivity implicate altered resting-state brain activity in individuals with chronic pain. ${ }^{72}$ Several resting-state networks show increased or decreased functional connectivity in chronic pain. ${ }^{73}$ These include the default-mode networks $(\mathrm{DMN}),{ }^{74}$ regions more active at rest; salience and executive control networks, regions more active during sensory stimulation or tasks; and sensory-motor networks, regions related to sensory and motor processes. 
Altered DMN function in chronic pain states has been demonstrated also using arterial spin labeling fMRI. ${ }^{75}$

In cLBP, decreased functional connectivity within the DMN has been observed, in particular among regions of the medial PFC, posterior cingulate cortex, and amygdala. ${ }^{76}$ In FM, increased functional connectivity has been observed within the DMN and executive attention network. ${ }^{77}$ Greater connectivity between the DMN and insular cortex has also been observed in FM, which suggests the relationship between these regions is altered in FM. ${ }^{77}$ Similar alterations in the relationship between the insular cortex and other cortical regions have been observed in other studies of FM as well. ${ }^{78}$ Alterations in the low-frequency fluctuations within the primary somatosensory cortex, supplementary motor area, dorsolateral prefrontal cortex, and amygdala also have been observed in chronic pain. ${ }^{79}$ Decreased functional connectivity within the DMN and increased functional connectivity within sensory, motor, and other pain-processing regions occurs in CRPS. ${ }^{80}$ In CPP, altered resting-state activity occurs in sensory-motor regions ${ }^{81}$ and within the DMN. ${ }^{82}$ Additional research has demonstrated that altered functional connectivity of the brainstem, ${ }^{83}$ basal ganglia, ${ }^{84}$ and regions of the frontal and temporal cortices ${ }^{85}$ occur in chronic migraine. Similar alterations in resting-state activity have been shown to occur in diabetic neuropathic pain. ${ }^{86}$

\section{Multivariate Analysis of Neuroimaging Data}

Multivariate pattern analysis (MVPA) uses machine-learning technology and is ideal for analysis of large neuroimaging data sets (for review see Ref. ${ }^{87}$ ). MVPA also can be used to identify signature patterns of changes in brain structure and function that may represent subgroups of patients with chronic pain. Additionally, MVPA can function as a prediction tool. Once a chronic pain signature pattern has been identified, data from a single individual can be classified (eg, as belonging to a healthy person or person with chronic pain) based on its similarity to the originally identified signature pattern of chronic pain. ${ }^{88}$ MVPA technology has been used to identify acute pain-related changes in healthy human volunteers, ${ }^{11}$ and can be used to differentiate patients with chronic pain from healthy volunteers based on brain structure. ${ }^{3,9}$

MVPA technology may make neuroimaging useful as a diagnostic tool. It may provide the ability to predict an individual patient's prognosis and to define the appropriate therapy based on an individual patient's brain structure and activity patterns (Fig. 1). Overall, MVPA is a powerful tool that may greatly advance the clinical utility of neuroimaging for individuals with chronic pain and may help us to achieve the goal of precision pain medicine.

\section{Longitudinal Limitations of Chronic Pain Neuroimaging Research}

Most neuroimaging studies of chronic pain to date are cross-sectional. Therefore, causation of observed functional and structural changes cannot be inferred from most neuroimaging research. Longitudinal studies would allow tracking chronic pain from its onset and potentially causative information. Recently, some longitudinal investigations have been conducted, in $\mathrm{CLBP}^{89}$ and IBS. ${ }^{90}$ Changes in white matter structure have been shown paralleling the transition from subacute to $\mathrm{CLBP}^{91}$ Some brain changes are even reversed 
after treatment with effective therapies, ${ }^{92}$ for example, psychological therapy. ${ }^{93}$ Thus, although CNS alterations are abundant in chronic pain states, these alterations are likely not permanent. The use of appropriate and effective therapies may reduce chronic pain, and while doing so, restore normal brain structure and function (Box 2).

\section{Box 2}

\section{Neuroimaging-based therapies}

Several real-time neurofeedback studies have been conducted for chronic pain. ${ }^{94,95}$ Additional research studies and clinical trials are still needed.

Deep brain stimulation and motor cortex stimulation are invasive therapies. They are therefore used only for use in very severe, intractable cases of chronic pain. Newer tools are being developed to better select patients who will most likely benefit. ${ }^{96}$ Current techniques use adaptive models ${ }^{97}$ and target brain regions that have the potential to activate multiple downstream effects. ${ }^{98}$

Transcranial magnetic stimulation (TMS) is a noninvasive intervention to reduce symptoms of chronic pain. Clinical trials of TMS demonstrate reduced pain for days to weeks after treatment. ${ }^{99}$ Current TMS research objectives are to identify better brain region targets and delivery specifications (such as parameters and treatment frequency).

Novel advancements for the future use of neuroimaging in chronic pain-related therapy include the development of brain-computer interfaces using electrocorticography and visual feedback. Visual feedback may be a beneficial therapy for phantom limb pain. ${ }^{100}$

Data from Refs. ${ }^{94-100}$

\section{SUMMARY}

Neuroimaging research has opened a window to the brain. Evidence of altered brain structure and function has been found across most chronic pain conditions. Common chronic pain conditions of cLBP, FM, neuropathic pain, and TMD have been frequently investigated using neuroimaging. Now that neuroimaging has identified tangible alterations in brain structure and function, chronic pain is less often thought of with skepticism as a mere psychological representation. Numerous neuroimaging studies have repeatedly demonstrated extensively altered brain structure and function across multiple types of chronic pain.

A large amount of overlapping evidence has been collected, all of which suggests that altered brain mechanisms greatly contribute to chronic pain. Neuroimaging research has identified multiple brain regions involved in processes of pain, sensory, motor, cognitive, motivational, memory, emotion, and fear that are related to chronic pain. A challenge for clinical care of chronic pain remains the individual variability in the pain experience among patients, with each patient's condition being different from another's. Further research and future advances in neuroimaging technology may clarify how brain mechanisms are involved in chronic pain and allow for the development of novel neuroimaging-based therapies for chronic pain. 


\section{Acknowledgments}

Funding Sources: K99 DA040154, K24 DA29262 and the Redlich Pain Research Endowment. Department of Anesthesiology, Perioperative and Pain Medicine, Division of Pain Medicine, Stanford Systems Neuroscience and Pain Lab (SNAPL), 1070 Arastradero Road, Suite 200, MC 5596, Palo Alto, CA 94304-1345, USA

Special thanks to Dr Ming-Chih Kao for designing Fig. 1.

\section{References}

1. IOM. Relieving pain in America: a blueprint for transforming prevention, care, education, and research. Washington, DC: IOM; 2011.

2. Mackey SC. Central neuroimaging of pain. J Pain. 2013; 14(4):328-31. [PubMed: 23548485]

3. Ung H, Brown JE, Johnson KA, et al. Multivariate classification of structural MRI data detects chronic low back pain. Cereb Cortex. 2014; 24(4):1037-44. [PubMed: 23246778]

4. Staud R. Brain imaging in fibromyalgia syndrome. Clin Exp Rheumatol. 2011; 29(6 Suppl 69):S109-17. [PubMed: 22243558]

5. Howard MA, Sanders D, Krause K, et al. Alterations in resting-state regional cerebral blood flow demonstrate ongoing pain in osteoarthritis: an arterial spin-labeled magnetic resonance imaging study. Arthritis Rheum. 2012; 64(12):3936-46. [PubMed: 22933378]

6. Barad MJ, Ueno T, Younger J, et al. Complex regional pain syndrome is associated with structural abnormalities in pain-related regions of the human brain. J Pain. 2014; 15(2):197-203. [PubMed: 24212070]

7. Chiapparini L, Ferraro S, Grazzi L, et al. Neuroimaging in chronic migraine. Neurol Sci. 2010; 31(Suppl 1):S19-22. [PubMed: 20464577]

8. Farmer MA, Chanda ML, Parks EL, et al. Brain functional and anatomical changes in chronic prostatitis/chronic pelvic pain syndrome. J Urol. 2011; 186(1):117-24. [PubMed: 21571326]

9. Bagarinao E, Johnson KA, Martucci KT, et al. Preliminary structural MRI based brain classification of chronic pelvic pain: a MAPP network study. Pain. 2014; 155(12):2502-9. [PubMed: 25242566]

10. Moisset X, Bouhassira D. Brain imaging of neuropathic pain. Neuroimage. 2007; 37(Suppl 1):S80-8. [PubMed: 17512757]

11. Brown JE, Chatterjee N, Younger J, et al. Towards a physiology-based measure of pain: patterns of human brain activity distinguish painful from non-painful thermal stimulation. PLoS One. 2011; 6(9):e24124. [PubMed: 21931652]

12. Jeffrey-Gauthier R, Guillemot JP, Piche M. Neurovascular coupling during nociceptive processing in the primary somatosensory cortex of the rat. Pain. 2013; 154(8):1434-41. [PubMed: 23707276]

13. Thompson SJ, Millecamps M, Aliaga A, et al. Metabolic brain activity suggestive of persistent pain in a rat model of neuropathic pain. Neuroimage. 2014; 91:344-52. [PubMed: 24462776]

14. Lawrence JM, Hoeft F, Sheau KE, et al. Strategy-dependent dissociation of the neural correlates involved in pain modulation. Anesthesiology. 2011; 115(4):844-51. [PubMed: 21934411]

15. Fairhurst M, Wiech K, Dunckley P, et al. Anticipatory brainstem activity predicts neural processing of pain in humans. Pain. 2007; 128(1-2):101-10. [PubMed: 17070996]

16. Ochsner KN, Zaki J, Hanelin J, et al. Your pain or mine? Common and distinct neural systems supporting the perception of pain in self and others. Soc Cogn Affect Neurosci. 2008; 3(2):144-60. [PubMed: 19015105]

17. Watson A, El-Deredy W, Iannetti GD, et al. Placebo conditioning and placebo analgesia modulate a common brain network during pain anticipation and perception. Pain. 2009; 145(1-2):24-30. [PubMed: 19523766]

18. Zeidan F, Martucci KT, Kraft RA, et al. Brain mechanisms supporting the modulation of pain by mindfulness meditation. J Neurosci. 2011; 31(14):5540-8. [PubMed: 21471390]

19. Ochsner KN, Ludlow DH, Knierim K, et al. Neural correlates of individual differences in painrelated fear and anxiety. Pain. 2006; 120(1-2):69-77. [PubMed: 16364548] 
20. Younger JW, Shen YF, Goddard G, et al. Chronic myofascial temporomandibular pain is associated with neural abnormalities in the trigeminal and limbic systems. Pain. 2010; 149(2):222-8. [PubMed: 20236763]

21. Logothetis NK. The underpinnings of the BOLD functional magnetic resonance imaging signal. $\mathrm{J}$ Neurosci. 2003; 23(10):3963-71. [PubMed: 12764080]

22. Widerstrom-Noga E, Pattany PM, Cruz-Almeida Y, et al. Metabolite concentrations in the anterior cingulate cortex predict high neuropathic pain impact after spinal cord injury. Pain. 2013; 154(2): 204-12. [PubMed: 23141478]

23. Williams DS. Quantitative perfusion imaging using arterial spin labeling. Methods Mol Med. 2006; 124:151-73. [PubMed: 16506421]

24. Price DD, Hu JW, Dubner R, et al. Peripheral suppression of first pain and central summation of second pain evoked by noxious heat pulses. Pain. 1977; 3(1):57-68. [PubMed: 876667]

25. Willis WD, Westlund KN. Neuroanatomy of the pain system and of the pathways that modulate pain. J Clin Neurophysiol. 1997; 14(1):2-31. [PubMed: 9013357]

26. Latremoliere A, Woolf CJ. Central sensitization: a generator of pain hypersensitivity by central neural plasticity. J Pain. 2009; 10(9):895-926. [PubMed: 19712899]

27. Woolf CJ. Central sensitization: implications for the diagnosis and treatment of pain. Pain. 2011; 152(3 Suppl):S2-15. [PubMed: 20961685]

28. Ashburner J, Friston KJ. Voxel-based morphometry-the methods. Neuroimage. 2000; 11(6 Pt 1): 805-21. [PubMed: 10860804]

29. Chung MK, Worsley KJ, Robbins S, et al. Deformation-based surface morphometry applied to gray matter deformation. Neuroimage. 2003; 18(2):198-213. [PubMed: 12595176]

30. Schmidt-Wilcke T, Leinisch E, Ganssbauer S, et al. Affective components and intensity of pain correlate with structural differences in gray matter in chronic back pain patients. Pain. 2006; 125(1-2):89-97. [PubMed: 16750298]

31. Kuchinad A, Schweinhardt P, Seminowicz DA, et al. Accelerated brain gray matter loss in fibromyalgia patients: premature aging of the brain? J Neurosci. 2007; 27(15):4004-7. [PubMed: 17428976]

32. Schmidt-Wilcke T, Ganssbauer S, Neuner T, et al. Subtle grey matter changes between migraine patients and healthy controls. Cephalalgia. 2008; 28(1):1-4.

33. Davis KD, Pope G, Chen J, et al. Cortical thinning in IBS: implications for homeostatic, attention, and pain processing. Neurology. 2008; 70(2):153-4. [PubMed: 17959767]

34. Baliki MN, Schnitzer TJ, Bauer WR, et al. Brain morphological signatures for chronic pain. PLoS One. 2011; 6(10):e26010. [PubMed: 22022493]

35. May A. Chronic pain may change the structure of the brain. Pain. 2008; 137(1):7-15. [PubMed: 18410991]

36. Smallwood RF, Laird AR, Ramage AE, et al. Structural brain anomalies and chronic pain: a quantitative meta-analysis of gray matter volume. J Pain. 2013; 14(7):663-75. [PubMed: 23685185]

37. Moayedi M, Weissman-Fogel I, Salomons TV, et al. White matter brain and trigeminal nerve abnormalities in temporomandibular disorder. Pain. 2012; 153(7):1467-77. [PubMed: 22647428]

38. Ellingson BM, Mayer E, Harris RJ, et al. Diffusion tensor imaging detects microstructural reorganization in the brain associated with chronic irritable bowel syndrome. Pain. 2013; 154(9): 1528-41. [PubMed: 23721972]

39. Farmer MA, Huang L, Martucci K, et al. Brain white matter abnormalities in female interstitial cystitis/bladder pain syndrome: a MAPP network neuroimaging study. J Urol. 2015; 194(1):11826. [PubMed: 25711200]

40. Geha PY, Baliki MN, Harden RN, et al. The brain in chronic CRPS pain: abnormal gray-white matter interactions in emotional and autonomic regions. Neuron. 2008; 60(4):570-81. [PubMed: 19038215]

41. Lutz J, Jager L, De Quervain D, et al. White and gray matter abnormalities in the brain of patients with fibromyalgia: a diffusion-tensor and volumetric imaging study. Arthritis Rheum. 2008; 58(12):3960-9. [PubMed: 19035484] 
42. Luerding R, Weigand T, Bogdahn U, et al. Working memory performance is correlated with local brain morphology in the medial frontal and anterior cingulate cortex in fibromyalgia patients: structural correlates of pain-cognition interaction. Brain. 2008; 131(Pt 12):3222-31. [PubMed: 18819988]

43. Jensen KB, Srinivasan P, Spaeth R, et al. Overlapping structural and functional brain changes in patients with long-term exposure to fibromyalgia pain. Arthritis Rheum. 2013; 65(12):3293-303. [PubMed: 23982850]

44. Derbyshire SW, Jones AK, Creed F, et al. Cerebral responses to noxious thermal stimulation in chronic low back pain patients and normal controls. Neuroimage. 2002; 16(1):158-68. [PubMed: 11969326]

45. Glass JM, Williams DA, Fernandez-Sanchez ML, et al. Executive function in chronic pain patients and healthy controls: different cortical activation during response inhibition in fibromyalgia. J Pain. 2011; 12(12):1219-29. [PubMed: 21945593]

46. Vachon-Presseau E, Martel MO, Roy M, et al. Acute stress contributes to individual differences in pain and pain-related brain activity in healthy and chronic pain patients. J Neurosci. 2013; 33(16): 6826-33. [PubMed: 23595741]

47. Baliki MN, Chialvo DR, Geha PY, et al. Chronic pain and the emotional brain: specific brain activity associated with spontaneous fluctuations of intensity of chronic back pain. J Neurosci. 2006; 26(47):12165-73. [PubMed: 17122041]

48. Apkarian AV, Bushnell MC, Treede RD, et al. Human brain mechanisms of pain perception and regulation in health and disease. Eur J Pain. 2005; 9(4):463-84. [PubMed: 15979027]

49. Vartiainen N, Kirveskari E, Kallio-Laine K, et al. Cortical reorganization in primary somatosensory cortex in patients with unilateral chronic pain. J Pain. 2009; 10(8):854-9. [PubMed: 19638329]

50. Rodriguez-Raecke R, Ihle K, Ritter C, et al. Neuronal differences between chronic low back pain and depression regarding long-term habituation to pain. Eur J Pain. 2014; 18(5):701-11. [PubMed: 24167119]

51. Kutch JJ, Yani MS, Asavasopon S, et al. Altered resting state neuromotor connectivity in men with chronic prostatitis/chronic pelvic pain syndrome: a MAPP: research network neuroimaging study. Neuroimage Clin. 2015; 8:493-502. [PubMed: 26106574]

52. Moulton EA, Elman I, Pendse G, et al. Aversion-related circuitry in the cerebellum: responses to noxious heat and unpleasant images. J Neurosci. 2011; 31(10):3795-804. [PubMed: 21389234]

53. Bechara A, Damasio H, Damasio AR. Emotion, decision making and the orbitofrontal cortex. Cereb Cortex. 2000; 10(3):295-307. [PubMed: 10731224]

54. Weissman-Fogel I, Moayedi M, Tenenbaum HC, et al. Abnormal cortical activity in patients with temporomandibular disorder evoked by cognitive and emotional tasks. Pain. 2011; 152(2):384-96. [PubMed: 21167644]

55. Kucyi A, Salomons TV, Davis KD. Mind wandering away from pain dynamically engages antinociceptive and default mode brain networks. Proc Natl Acad Sci U S A. 2013; 110(46): 18692-7. [PubMed: 24167282]

56. Gu X, Gao Z, Wang X, et al. Anterior insular cortex is necessary for empathetic pain perception. Brain. 2012; 135(Pt 9):2726-35. [PubMed: 22961548]

57. Rainville P, Duncan GH, Price DD, et al. Pain affect encoded in human anterior cingulate but not somatosensory cortex. Science. 1997; 277(5328):968-71. [PubMed: 9252330]

58. Noll-Hussong M, Otti A, Wohlschlaeger AM, et al. Neural correlates of deficits in pain-related affective meaning construction in patients with chronic pain disorder. Psychosom Med. 2013; 75(2):124-36. [PubMed: 23362496]

59. Simons LE, Moulton EA, Linnman C, et al. The human amygdala and pain: evidence from neuroimaging. Hum Brain Mapp. 2014; 35(2):527-38. [PubMed: 23097300]

60. Aoki Y, Inokuchi R, Suwa H. Reduced N-acetylaspartate in the hippocampus in patients with fibromyalgia: a meta-analysis. Psychiatry Res. 2013; 213(3):242-8. [PubMed: 23835064]

61. Barke A, Baudewig J, Schmidt-Samoa C, et al. Neural correlates of fear of movement in high and low fear-avoidant chronic low back pain patients: an event-related fMRI study. Pain. 2012; 153(3): 540-52. [PubMed: 22230805] 
62. Nandi D, Liu X, Joint C, et al. Thalamic field potentials during deep brain stimulation of periventricular gray in chronic pain. Pain. 2002; 97(1-2):47-51. [PubMed: 12031778]

63. Baliki MN, Geha PY, Fields HL, et al. Predicting value of pain and analgesia: nucleus accumbens response to noxious stimuli changes in the presence of chronic pain. Neuron. 2010; 66(1):149-60. [PubMed: 20399736]

64. Loggia ML, Berna C, Kim J, et al. Disrupted brain circuitry for pain-related reward/punishment in fibromyalgia. Arthritis Rheum. 2014; 66(1):203-12.

65. Wood PB. Stress and dopamine: implications for the pathophysiology of chronic widespread pain. Med Hypotheses. 2004; 62(3):420-4. [PubMed: 14975515]

66. Berman SM, Naliboff BD, Suyenobu B, et al. Reduced brainstem inhibition during anticipated pelvic visceral pain correlates with enhanced brain response to the visceral stimulus in women with irritable bowel syndrome. J Neurosci. 2008; 28(2):349-59. [PubMed: 18184777]

67. Heinricher MM, Tavares I, Leith JL, et al. Descending control of nociception: specificity, recruitment and plasticity. Brain Res Rev. 2009; 60(1):214-25. [PubMed: 19146877]

68. Nash P, Wiley K, Brown J, et al. Functional magnetic resonance imaging identifies somatotopic organization of nociception in the human spinal cord. Pain. 2013; 154(6):776-81. [PubMed: 23618495]

69. Summers PE, Ferraro D, Duzzi D, et al. A quantitative comparison of BOLD fMRI responses to noxious and innocuous stimuli in the human spinal cord. Neuroimage. 2010; 50(4):1408-15. [PubMed: 20096788]

70. Summers PE, Iannetti GD, Porro CA. Functional exploration of the human spinal cord during voluntary movement and somatosensory stimulation. Magn Reson Imaging. 2010; 28(8):1216-24. [PubMed: 20573462]

71. Fox MD, Snyder AZ, Vincent JL, et al. The human brain is intrinsically organized into dynamic, anticorrelated functional networks. Proc Natl Acad Sci U S A. 2005; 102(27):9673-8. [PubMed: 15976020]

72. Fox MD, Raichle ME. Spontaneous fluctuations in brain activity observed with functional magnetic resonance imaging. Nat Rev Neurosci. 2007; 8(9):700-11. [PubMed: 17704812]

73. Smith SM, Fox PT, Miller KL, et al. Correspondence of the brain's functional architecture during activation and rest. Proc Natl Acad Sci U S A. 2009; 106(31):13040-5. [PubMed: 19620724]

74. Greicius MD, Krasnow B, Reiss AL, et al. Functional connectivity in the resting brain: a network analysis of the default mode hypothesis. Proc Natl Acad Sci U S A. 2003; 100(1):253-8. [PubMed: 12506194]

75. Loggia ML, Kim J, Gollub RL, et al. Default mode network connectivity encodes clinical pain: an arterial spin labeling study. Pain. 2013; 154(1):24-33. [PubMed: 23111164]

76. Baliki MN, Geha PY, Apkarian AV, et al. Beyond feeling: chronic pain hurts the brain, disrupting the default-mode network dynamics. J Neurosci. 2008; 28(6):1398-403. [PubMed: 18256259]

77. Napadow V, Lacount L, Park K, et al. Intrinsic brain connectivity in fibromyalgia is associated with chronic pain intensity. Arthritis Rheum. 2010; 62(8):2545-55. [PubMed: 20506181]

78. Cifre I, Sitges C, Fraiman D, et al. Disrupted functional connectivity of the pain network in fibromyalgia. Psychosom Med. 2012; 74(1):55-62. [PubMed: 22210242]

79. Kim JY, Kim SH, Seo J, et al. Increased power spectral density in resting-state pain-related brain networks in fibromyalgia. Pain. 2013; 154(9):1792-7. [PubMed: 23714266]

80. Bolwerk A, Seifert F, Maihofner C. Altered resting-state functional connectivity in complex regional pain syndrome. J Pain. 2013; 14(10):1107-15. e8. [PubMed: 23791136]

81. Kilpatrick LA, Kutch JJ, Tillisch K, et al. Alterations in resting state oscillations and connectivity in sensory and motor networks in women with interstitial cystitis/painful bladder syndrome. $\mathrm{J}$ Urol. 2014; 192(3):947-55. [PubMed: 24681331]

82. Martucci KT, Shirer WR, Bagarinao E, et al. The posterior medial cortex in urologic chronic pelvic pain syndrome: detachment from default mode network-a resting-state study from the MAPP Research Network. Pain. 2015; 156(9):1755-64. [PubMed: 26010458]

83. Mainero C, Boshyan J, Hadjikhani N. Altered functional magnetic resonance imaging resting-state connectivity in periaqueductal gray networks in migraine. Ann Neurol. 2011; 70(5):838-45. [PubMed: 22162064] 
84. Yuan K, Zhao L, Cheng P, et al. Altered structure and resting-state functional connectivity of the basal ganglia in migraine patients without aura. J Pain. 2013; 14(8):836-44. [PubMed: 23669074]

85. Schwedt TJ, Larson-Prior L, Coalson RS, et al. Allodynia and descending pain modulation in migraine: a resting state functional connectivity analysis. Pain Med. 2014; 15(1):154-65. [PubMed: 24165094]

86. Cauda F, D'agata F, Sacco K, et al. Altered resting state attentional networks in diabetic neuropathic pain. J Neurol Neurosurg Psychiatry. 2010; 81(7):806-11. [PubMed: 19955113]

87. Orru G, Pettersson-Yeo W, Marquand AF, et al. Using support vector machine to identify imaging biomarkers of neurological and psychiatric disease: a critical review. Neurosci Biobehav Rev. 2012; 36(4):1140-52. [PubMed: 22305994]

88. Iuculano T, Rosenberg-Lee M, Supekar K, et al. Brain organization underlying superior mathematical abilities in children with autism. Biol Psychiatry. 2014; 75(3):223-30. [PubMed: 23954299]

89. Hashmi JA, Baliki MN, Huang L, et al. Shape shifting pain: chronification of back pain shifts brain representation from nociceptive to emotional circuits. Brain. 2013; 136(Pt 9):2751-68. [PubMed: 23983029]

90. Naliboff BD, Berman S, Suyenobu B, et al. Longitudinal change in perceptual and brain activation response to visceral stimuli in irritable bowel syndrome patients. Gastroenterology. 2006; 131(2): 352-65. [PubMed: 16890589]

91. Mansour AR, Baliki MN, Huang L, et al. Brain white matter structural properties predict transition to chronic pain. Pain. 2013; 154(10):2160-8. [PubMed: 24040975]

92. Seminowicz DA, Wideman TH, Naso L, et al. Effective treatment of chronic low back pain in humans reverses abnormal brain anatomy and function. J Neurosci. 2011; 31(20):7540-50. [PubMed: 21593339]

93. Jensen KB, Kosek E, Wicksell R, et al. Cognitive Behavioral Therapy increases pain-evoked activation of the prefrontal cortex in patients with fibromyalgia. Pain. 2012; 153(7):1495-503. [PubMed: 22617632]

94. Decharms RC, Maeda F, Glover GH, et al. Control over brain activation and pain learned by using real-time functional MRI. Proc Natl Acad Sci U S A. 2005; 102(51):18626-31. [PubMed: 16352728]

95. Chapin H, Bagarinao E, Mackey S. Real-time fMRI applied to pain management. Neurosci Lett. 2012; 520(2):174-81. [PubMed: 22414861]

96. Baron R, Backonja MM, Eldridge P, et al. Refractory Chronic Pain Screening Tool (RCPST): a feasibility study to assess practicality and validity of identifying potential neurostimulation candidates. Pain Med. 2014; 15(2):281-91. [PubMed: 24524843]

97. Schultz DM, Webster L, Kosek P, et al. Sensor-driven position-adaptive spinal cord stimulation for chronic pain. Pain Physician. 2012; 15(1):1-12. [PubMed: 22270733]

98. Garcia-Larrea L, Peyron R. Motor cortex stimulation for neuropathic pain: from phenomenology to mechanisms. Neuroimage. 2007; 37(Suppl 1):S71-9. [PubMed: 17644413]

99. Lefaucheur JP, Hatem S, Nineb A, et al. Somatotopic organization of the analgesic effects of motor cortex rTMS in neuropathic pain. Neurology. 2006; 67(11):1998-2004. [PubMed: 17159107]

100. Walter, A., Naros, N., Roth, A., et al. A brain-computer interface for chronic pain patients using epidural ECoG and visual feedback. Proceedings of the 2012 IEEE 12th International Conference on Bioinformatics \& Bioengineering (BIBE); Larnaca, Cyprus. November 11-13, 2012; 


\section{KEY POINTS}

- No single region within the central nervous system is responsible for chronic pain; altered brain structure and function occurs across many regions of the brain, brainstem, and spinal cord.

- $\quad$ Resting-state functional MRI (fMRI) has revealed multiregional alterations in brain function within various resting-state networks, including the salience, executive control, and default-mode networks.

- Multivariate pattern analysis (MVPA) is a new and powerful technology that allows for a whole-brain approach to identify altered brain structure and function in chronic pain. MVPA may ultimately help to develop brain-based objective biomarkers of pain and achieve the goal of precision pain management.

- $\quad$ Researchers are now using neuroimaging to identify brain targets for novel and effective treatments for chronic pain, such as transcranial magnetic stimulation, real-time fMRI, and other neuroimaging-based therapies. 


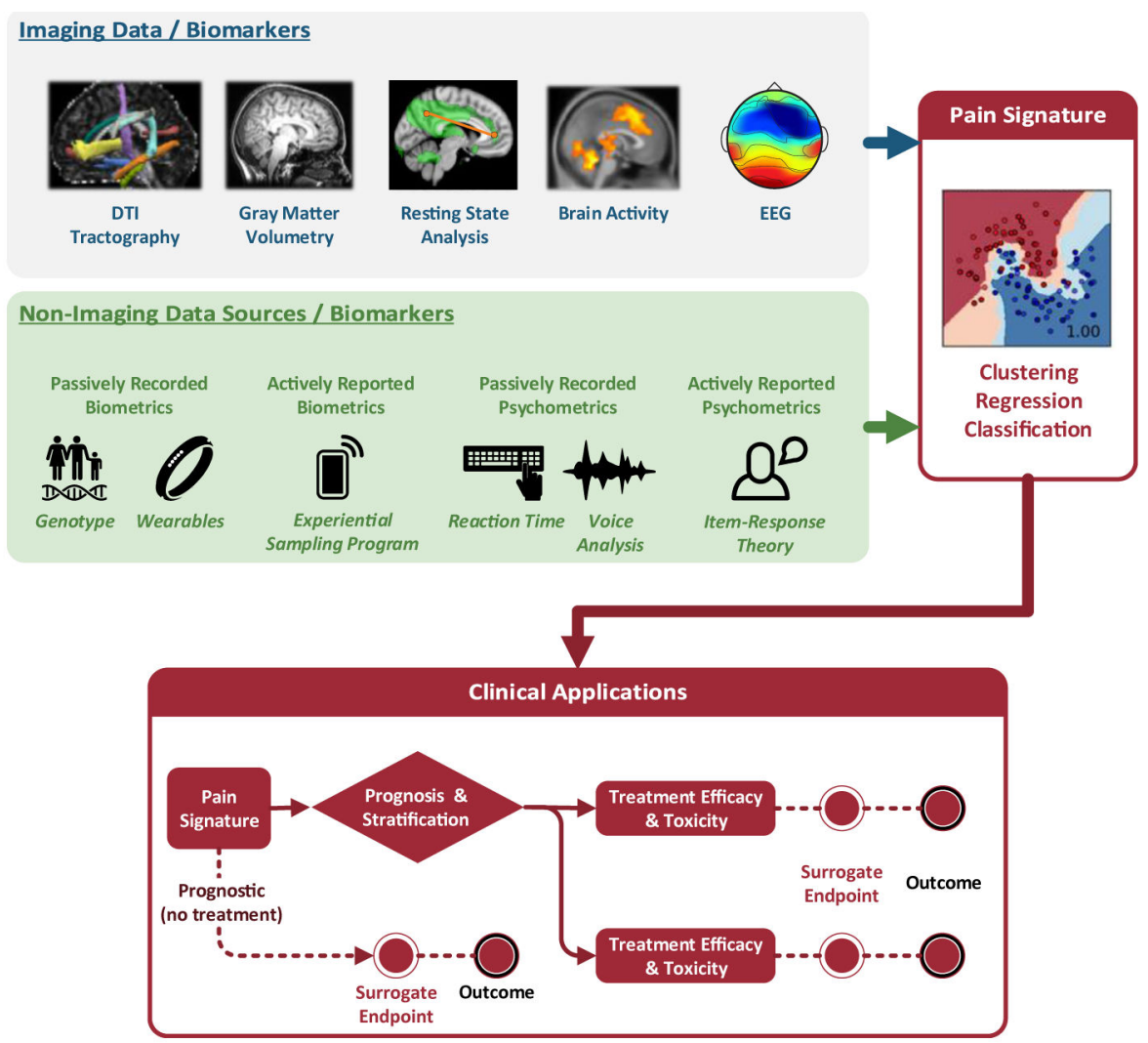

Fig. 1.

Schematic of data sources and clinical applications related to identification of pain signature patterns imaging data can provide large sources of detailed and objective biomarkers for pain (top, gray box). Various sources of imaging biomarkers include (1) structural abnormalities measured with MRI (eg, DTI of white matter tractography; gray matter volumetry), (2) functional differences measured with fMRI (eg, resting-state fMRI networks and functional connectivity between brain regions; brain activity in response to evoked stimulation or during a task), and (3) functional differences measured with non-MRI modalities, such as EEG. Nonimaging data sources can provide additional objective biomarkers (middle, green box). These include, for example, genotype information, biometrics from wearable technology (eg, actigraphy), actively reported biometrics (eg, via handheld devices for recording patients' symptoms throughout the day), psychometrics including reaction time tests and voice analysis (eg, to measure emotional states, such as depression or anxiety) and actively reported psychometrics (ie, demographic, psychological, and clinical questionnaires). The identified biomarkers from both imaging and nonimaging sources can be combined as input for an MVPA. The MVPA uses clustering, regression, and/or classification technology and is capable of identifying the most meaningful biomarkers to provide a multivariable signature pattern of pain (right, red box). The MVPAderived pain signature can then be used in a variety of clinical applications (bottom, red box). Starting as a complex prognostic measure, the pain signature could provide the basis for stratification of an individual to a specific treatment program ("Prognosis \& Stratification”). Surrogate endpoints, follow-up measurements after treatment, could be used 
to evaluate the treatment as effective or noneffective for the individual patient. Ultimately, the final outcome measures would indicate the pain signature's prognostic sensitivity and specificity. Alternatively, as a more traditional clinical course of action ("Prognostic [no treatment]"), the pain signature could be used simply as a diagnostic (for clinical or legal purposes) or to predict a patient's prognosis over time regardless of treatment. (Courtesy of Ming-Chih Kao, PhD, MD, Palo Alto, CA.) 